\title{
The effectiveness of applying beta-coefficient modifications when calculating returns on shares in Russian companies
}

\author{
Valentina ZOZULYA*, Evgeny SOKOLOV**, \\ Evgeny KOSTYRIN***, Sergey KOROLEV*****
}

\begin{abstract}
This article analyzes the effectiveness of various beta coefficient modifications in forecasting on the Russian stock market. Objective: To test the hypothesis of the superiority of modified beta coefficients in forecast accuracy. Methods: Calculating and comparing the stock returns of ten companies that play a key role in the Russian economy based on three beta coefficient modifications: classic, Monkhouse, and two beta. The criteria were used for verifying sample homogeneity in order to test the hypothesis that modified beta coefficients produce more accurate forecasting. Results: The analysis showed that, in most cases, none of the three models obtained relevant results for the Russian companies. None of the modifications tested can be recognized with high confidence as more accurate than traditional beta coefficients. Conclusions: In the contemporary Russian stock market, the CAPM does not allow one to produce satisfactory forecasts on stock returns.
\end{abstract}

Keywords: beta, capital asset pricing model, modified beta, stock returns, test of homogeneity of samples

\section{Introduction}

The effective functioning of stock markets is closely linked to the growth of the national economy and its influence can be traced in both the short and long terms (Masoud, 2013). This is especially important for developing economies like the

\footnotetext{
*Valentina ZOZULYA is PhD in Economics at Bauman Moscow State Technical University, Moscow, Russia; e-mail: zva-inga@mail.ru.

${ }^{* *}$ Evgeny SOKOLOV is PhD in Engineering at Bauman Moscow State Technical University, Moscow, Russia; e-mail: ibm5-moskwa@rambler.ru.

${ }^{* * * *}$ Evgeny KOSTYRIN is PhD in Economics at Bauman Moscow State Technical University, Moscow, Russia; e-mail: mauntain76@mail.ru.

${ }^{* * * * *}$ Sergey KOROLEV is Master's student at Bauman Moscow State Technical University, Moscow, Russia; e-mail: korolev-s1998@yandex.ru.
} 
Russian one since international investors have an interest in investing in new markets that, compared to the developed ones, potentially offer higher returns (Cole et al., 2020). On the other hand, foreign investment can provide a more dynamic growth of the national economy.

Constant interest from investors in the instruments being traded is required for the effective functioning and development of a national stock exchange. The key to making arbitrage trading attractive is being able to make reliable predictions for returns on traded assets (Jadhav et al., 2015).

Currently, one of the most popular methods for assessing the required return on an asset is the capital asset pricing model (CAPM) (Kokotkina et al., 2017). The main component of this model is the beta coefficient. Its value is calculated using statistical data on the historical profitability of the asset being evaluated. The standard version of the model is based on a number of assumptions, which are not all present in real practice, in general.

The traditional beta coefficient is defined as the coefficient of the linear regression of an asset's return relative to the return on a market portfolio (Podkopaev, 2015). One of the main problems with this ratio, as Richard Roll points out in his work, "Criticism" (Roll, 1977), is that it is impossible to formulate a market portfolio as simultaneously completing transactions to sell all shares traded on the stock market is not physically possible. That is why a highly diversified portfolio that can be analyzed is used in real practice. A stock index often serves this purpose (Rossi, 2016). However, this model, despite its practical feasibility, has its drawbacks. Chief among them is the significant influence of the selected stock index on the final result (Glagoleva, 2008).

The next two factors that can negatively affect the accuracy of the forecast are: the choice of time period for which the beta coefficient is calculated and the time interval for which the profitability of the evaluated asset and the market index are measured. In his work, Aswath Damodaran (Damodaran, 1999) showed that, depending on the three above factors, the spread of beta coefficient values for the same asset can reach $70 \%$, which led to the appearance of a significant number of beta-coefficient modifications designed to improve the accuracy of forecasts on stock returns.

Therefore, to increase the practical applicability and accuracy of forecasting, the subsequent models were developed. These models extend the CAPM and modify the beta coefficient by introducing amendments that take into account the influence of various risk cofactors. Among the main directions, several ways for modifying beta coefficients may be distinguished. Levered betas consider the savings from the "tax shield", as well as, generally, the risk of debt. Lagged betas take on the particular stock delayed yield reaction to changes in the market. Downside betas assume that, among the investors, only a downward deviation from the expected return is deemed to be a risk. 
Moreover, some studies (Famaand French 1993) propose to introduce, along with the beta coefficient for market risk assessment, some extra factors that would manage other risks in the traded share returns predicting models. Since these factors are said to have a notable effect on stock returns, that cannot be explained by covariance with market risk.

The object of this study is to empirically test the hypothesis that applying levered and lagged groups modified betacoefficients increases the accuracy of forecasting returns on shares in Russian companies.

Applied to the Russian stock market, testing such an assumption is challenging since it is one of the five largest emerging stock markets (Banks Around the World, 2017). Yet, studies with unambiguously interpreted results on the most appropriate method for evaluating the profitability of the assets have not been carried out for it recently. Thus, the matter of choosing the relevant method can be considered open.

The global experience regarding the predominance of modified beta coefficients and CAPM versions over the traditional ones does not show any consensus either. An analysis of historical data on shares traded on the Brussels Stock Exchange showed that the accuracy of predictions obtained using various beta coefficients was not stable (Mensah, 2013). In this study, forecasts were made for non-overlapping five-year periods from 1832 to 1914 with consideration of monthly stock returns. The use of modified beta coefficients based on autoregression and aggregation of stocks into portfolios of 10 stocks or more allowed obtaining predictions of significantly higher accuracy according to the root mean squared error criterion compared to the traditional CAPM model applied for individual stocks.

A study using stocks traded on the Istanbul Stock Exchange came to the conclusion that the modified "threshold" beta coefficient is superior to the traditional one (Yayvak et al., 2015). This study was conducted based on weighted industrial portfolios for the main sectors of the economy, with monthly returns analysis for the period from January 1998 to December 2011. As a measure of comparison of the prediction error, the root mean squared error was used, which turned out to be lower for all industrial portfolios applying the "threshold" beta coefficient versus traditional beta.

Similar conclusions about the superiority of the modified CAPM over the traditional one were obtained by Indian researchers (Bajpai and Sharma, 2015). In this paper, the selected basis is related to the daily returns of portfolios composed of stocks of NSE CNX 500 for ten years from January 1, 2004, to December 31, 2013, from which a sliding window of three years was formed. The traditional CAPM was compared to the model, in which the beta coefficient was calculated as a regression coefficient for the model without a constant. For the resulting forecasts the value of the F-statistic was calculated, which, in the case of the modified model, turned out to be significant for $62 \%$ of sub-periods, while in the traditional model, there were no such sub-periods. 
Serbian authors who analyzed the Belgrade Stock Exchange concluded that using a modified beta coefficient, as well as its traditional variation, does not allow for satisfactory forecasting (Stancic et al., 2015). This study was based on data of monthly returns on shares of 10 Serbian companies from January 2010 to December 2014. Employing regression analysis, corresponding values of the traditional beta coefficient and conditional CAPM coefficients were estimated, considering the difference value between the expected market return and the risk-free rate, which in the case of an emerging market might be negative (Verma, 2011). The obtained regression models were checked for the significance of the regression and determination coefficients. As a result, both models were concluded to have statistically insignificant regression coefficients, which indicates their low predictive power.

An analysis of the applicability of the traditional CAPM in the Russian stock market using the example of MegaFon PJSC (Public Joint-Stock Company), showed that the traditional beta coefficient has weak predictive capabilities and should not be considered as a tool for forecasting future returns on Russian stocks. The author considers the use of hybrid models more appropriate, in particular, the Lessard model (Dedyuhin, 2019). In this paper, the analysis was based on the daily stock return for five years from 2013 to 2018. The value of the traditional beta coefficient was calculated by using regression analysis but for the resulting model, the determination coefficient value remained below 0.218, rendering the traditional model unsatisfactory, and it was proposed to use a hybrid model based on the return on shares of a comparable company operating in a developed market. However, the forecast from the Lessard model was not compared with the actual value, which would enable concluding about the accuracy of this model.

A large-scale study conducted by researchers from the Financial University under the Government of the Russian Federation revealed the superiority of a modified beta coefficient that considers non-trading risk over a traditional one on the Russian stock market (Fedorova et al., 2017). It reviewed the quotes of shares of 260 Russian companies from various sectors of the economy in the period from 2010 to 2016. The corresponding traditional and modified beta coefficient was calculated by considering the dependence of the profitability of a particular asset on the profitability of a nontradable asset. These coefficients were compared with each other, and the conclusion about the superiority of the modified beta coefficient over the traditional one was drawn on the grounds that the values of the modified beta are higher than the traditional one, provided that the traditional beta is greater than unity, which should indicate a more accurate accounting of nontradable risk for low-liquid stocks (Hur and Chung, 2017). However, the accuracy of predictions obtained using various beta coefficients, as well as in the previous work, has not been verified.

Thus, it can be noted that, although most research in emerging markets has led to the conclusion that modified CAPMs and beta coefficients are superior to traditional ones, there are also counter examples. At the same time, recent studies conducted on the Russian market provide judgments about the superiority of 
modified coefficients over traditional ones driven by indirect indicators only. Besides, the reviewed studies did not address the use of beta coefficients that take into account capital structure and the risk of debt. Therefore, it can be argued that the superiority of modified beta coefficients over traditional ones is not consistent for all markets, and therefore, requires testing on Russian companies.

This work is a continuation of a previously published study (Zozulya and Korolev, 2018) devoted to analyzing the applicability of various beta-coefficient modifications proposed in the last fifty years in the conditions of the Russian economy. In this work, we continued that research by expanding the pool of companies analyzed and by considering three beta coefficient modifications proposed by leading scientists.

\section{Methodology}

In a previous work, we conducted a comparative analysis of Sharpe and Monkhouse beta coefficients for the largest Russian company, Gazprom, and we came to the conclusion that the formula proposed by Peter H.L. Monkhouse is more accurate (Zozulya and Korolev, 2018). In order to further test this hypothesis in this article, the sample was expanded to 10 large public Russian companies representing various sectors of the national economy. The reason why the large companies' shares have been selected for analysis is that their functioning is more stable, and, hypothetically, profitability, in this case, can be better described by the CAPM. After that, for the large companies, the published sources provide more information necessary to assess the risk of debt.

For comparison, we selected representatives of the following industries: oil and gas (PJSC Gazprom, PJSC NK Rosneft), banking (PJSC Sberbank of Russia, PJSC Bank VTB), insurance (PJSC SK (Insurance Company) Rosgosstrakh), energy (PJSC MOESK, PJSC RusHydro), investing (PJSC AFK (Joint-Stock Financial Corporation) Sistema), automotive (PJSC KAMAZ) and communications services (PJSC MTS). These industries are among the most developed in the Russian economy (Analytical Center for the Government of the Russian Federation, 2019), and the companies in question hold leading positions. It is assumed that, in response to the selected compilation of companies, the results of the research carried out can be correctly generalized to the shares of the entire Russian companies traded on the Moscow Exchange.

For each of these companies, the following were calculated: the traditional Sharpe coefficient, the Monkhouse beta coefficient and the two beta model coefficient.

The traditional beta coefficient is calculated by using formula (1):

$$
\beta=\frac{\operatorname{Cov}\left(r_{a}, r_{p}\right)}{\operatorname{Var}\left(r_{p}\right)}
$$

where: 
$r_{a}$ is the estimated value for which the beta coefficient is calculated: the return on shares of the company in question;

$r_{p}$ is the reference value used to compare profitability with the market index;

Cov is the covariance of the estimated and reference values;

Var is the dispersion of the reference value (Bukhvalov, 2016).

The accuracy of the predictions based on this coefficient represents a reference point when analyzing the results provided by the modified beta coefficients.

This coefficient does not consider the impact of taxes and transaction costs on the company's stock return. This is why one of the most important areas for modifying the beta coefficient is taking into account the capital structure of the company being evaluated. Obviously, by attracting borrowed financing, a company exposes its shareholders to more risk. From the levered coefficient group, we chose the coefficient proposed by Peter H.L. Monkhouse, since it simultaneously takes into account the risk of corporate debt and the weighted average cost of borrowed capital, which affects the size of tax savings. Thus, it integrates the adjustments proposed separately in earlier modifications of the levered beta coefficients.

The Monkhouse beta coefficient for a company using borrowed financing is determined by formula (2):

$$
\beta_{L}=\beta_{U}+\left(\beta_{U}-\beta_{D}\right) \cdot\left(1-(1-\gamma) \cdot\left(\frac{k_{d}}{1+k_{d}}\right) \cdot T_{e}\right) \cdot L
$$

where:

$\beta_{\mathrm{L}}$ is the beta value for the company using blended financing;

$\beta_{\mathrm{U}}$ is the beta coefficient value for a company that does not use borrowed financing; $\beta_{\mathrm{D}}$ is the beta of debt;

$\gamma$ is a parameter reflecting the ability of investors to use tax incentives;

$\mathrm{Te}$ reflects the income tax rate in effect;

$\mathrm{k}_{\mathrm{d}}$ is the weighted average cost of borrowed capital;

$\mathrm{L}$ is financial leverage, the debt to equity ratio (Monkhouse, 1997).

The final parameter is relevant for the New Zealand market, where there is a double taxation avoidance law according to which a shareholder sometimes has the right not to pay taxes on dividends if the company they hold shares in has already paid income tax (Money Online Ltd and Investment Research Group Ltd, 2002).

In countries where such a law does not exist, in Russia, in particular, formula (2) is converted to formula (3):

$$
\beta_{L}=\beta_{U}+\left(\beta_{U}-\beta_{D}\right) \cdot\left(1-\left(\frac{k_{d}}{1+k_{d}}\right) \cdot T_{e}\right) \cdot L
$$

The next direction where a significant number of beta coefficient modifications has been developed is associated with long-term stability. It is obvious that, at some points, in the market, as well as in individual companies, crisis phenomena can occur, which may be offset in some time. It is assumed that sampling profitability over several long-term periods allows us to level out to a large extent 
the effect of fluctuating sales volumes for specific shares on the final value of the modified beta coefficient (Chang, 2015).

Also, lagged beta coefficients make it possible to take into account delayed responses in the yield of individual assets to changes in market conditions. Such a reaction is typical for stocks in companies operating in emerging financial markets (Semenyuk, 2016) like Russia.

Among the lagged beta coefficients, we chose the two beta model. The idea behind this model is that the final beta coefficient is defined as the weighted average of the one-year and five-year coefficients:

$$
\beta=\omega_{L} \cdot \beta_{L}+\omega_{S} \cdot \beta_{S}
$$

where:

$\beta_{\mathrm{L}}$ is the value of the beta coefficient for a period of five years;

$\beta_{\mathrm{S}}$ is the value of the beta coefficient for a period of one year;

$\omega_{\mathrm{L}}$ is the weight of the long-term beta coefficient;

$\omega_{\mathrm{S}}$ is the weight of the short-term beta coefficient (Hamidreza and Amin, 2015).

Using the beta coefficients obtained, the stock return values of the companies were calculated and compared with the actual values.

To calculate the predicted value, the main CAPM formula was used (5).

$$
E\left(r_{a}\right)=R_{f}+\beta\left(E\left(r_{m}\right)-R_{f}\right)
$$

where:

$E\left(r_{a}\right)$ is the expected return on the asset;

$\mathrm{R}_{\mathrm{f}}$ is the risk-free rate of return;

$\beta$ is the beta coefficient for the asset;

$\mathrm{E}\left(\mathrm{r}_{\mathrm{m}}\right)$ is the expected profitability of the market (market index) (Bukhvalov, 2016).

In order to determine probable reasons for the discrepancy in the absolute value of errors made when forecasting stock returns by using various beta coefficient modifications, statistical criteria must be used for checking sample homogeneity (Orlov, 2016). In this way, it is checked whether there are statistically valid reasons to believe that the difference in forecasting accuracy for the provided companies picking is due to random factors or is a reflection of the real difference in the mean forecasting accuracy using various modifications of beta coefficients, which could be observed for the general population of all Russian companies whose shares are traded on the stock market.

Samples of discrepancies between predicted, using various beta coefficients, and actual returns are relative. To check the difference in averages, a one-sided twosample Student's t-test can be applied, which is calculated by using formula (6):

where:

$$
t=\frac{M_{d}}{s_{d} / \sqrt{n}}
$$

$\mathrm{M}_{\mathrm{d}}$ is the average absolute difference in values; 
$\mathrm{S}_{\mathrm{d}}$ is the unbiased estimate of the standard deviation of the differences; $\mathrm{n}$ is the number of elements in the sample.

The hypothesis of sample heterogeneity is accepted when the critical value is exceeded.

Also, to check homogeneity, one can use the ranking criteria of the Mann Whitney U-test (7) and the Wilcoxon signed-rank test (8). These are extra-applied criteria since they are much more resistant to outliers than the Student's test, but they do not consider the spread of values (Lemeshko and Lemeshko 2008).

$$
U=n_{1} n_{2}+\frac{n_{x}\left(n_{x}+1\right)}{2}-T_{x}
$$

where:

$\mathrm{n}_{1}$ is the number of elements in the first sample;

$\mathrm{n}_{2}$ is the number of elements in the second sample;

$\mathrm{T}_{\mathrm{x}}$ is the largest sum of ranks obtained by ranking the combined sample;

$\mathrm{n}_{\mathrm{x}}$ is the number of elements in the sample with a higher sum of ranks.

The hypothesis that there is a significant difference in the level of the observed trait is accepted when the statistical value $U$ is less than the critical value.

To calculate the statistics of the Wilcoxon T-test (Wilcoxon signed-rank test), the differences in the values of related elements in two samples are calculated. They are ranked by absolute value, then the sum of ranks for the positive $-R_{p}$ and negative - $\mathrm{R}_{\mathrm{n}}$ differences are calculated:

$$
T=\min \left\{R_{n} ; R_{p}\right\}
$$

The hypothesis of sample heterogeneity is accepted if the calculated value of statistic $\mathrm{T}$ is less than the table value (Vukolov, 2012).

Thus, if the hypothesis of homogeneity is rejected at a given level of significance, then it may be concluded that one of the beta coefficients is superior in the profitability accuracy prediction of Russian stocks over the other. Which respectfully justifies its use in forecasting. If the hypothesis of homogeneity is not rejected, it means that the modified beta coefficients do not have a statistically significant advantage in the accuracy of predicting stock returns. And since, from a practical point of view, their calculation is more difficult due to a larger volume of input data required, they cannot be considered as an effective tool for predicting the profitability of shares of Russian companies.

The use of three criteria, if their results are consistent, enables more confidently concluding on the presence or absence of superiority in the accuracy of the forecasts obtained by using the modified beta coefficients. Meanwhile, in the case of a significant mismatch in the criteria, additional analysis of the reasons for the deviations may be required to determine the observations for which of the companies led to such mismatch. 
Alongside the statistical criteria described above, which allow passing direct judgment upon the quality of forecasting, statistical criteria that indirectly indicate the correctness of the model applied are also available. On their basis, it is impossible to conclude the high forecasting accuracy or the superiority of one beta coefficient over another; however, it may indicate that the forecasts obtained using the model do not correspond to the situation actually observed in the stock market.

Hence, the correspondence of forecasting methods to the real results observed in trading can be separately confirmed or refuted by checking the hypothesis of the equality of the sample variances for the actual and predicted profitability values. This can be done by employing Fisher's F-test (F-test), the main statistics of which is calculated by the formula (9):

$$
F=\frac{s_{1}^{2}}{s_{2}^{2}}
$$

where:

$$
\begin{aligned}
& s_{1}^{2}-\text { is major of the compared unbiased sample variance; } \\
& s_{2}^{2}-\text { minor of the compared unbiased sample variance. }
\end{aligned}
$$

The equality of variances hypothesis in two general populations is rejected if the critical value is statistically exceeded. Obviously, if the variance of the stock returns of different companies predicted by the model is significantly less than the variance of the actual returns for the same companies, this model cannot be considered a reliable forecasting tool for the selected time horizon (Korolevand Yazev 2020). Still, the acceptance of the equality of variances hypothesis for the actual and predicted stock returns gives no reason to conclude upon the acceptable quality of forecasts from the analyzed beta coefficient modification.

The permanence of the regression dependence of market profitability and asset profitability over the analysis horizon was verified utilizing the Chow test for the presence of a structural break, during which the original sample was divided into two periods, the first of which included two-thirds of the early observations. Its statistics are calculated by the formula (10):

where:

$$
F=\frac{\left(R S S-R S S_{1}-R S S_{2}\right) / k}{\left(R S S_{1}+R S S_{2}\right) /(n-2 k)}
$$

RSS is sum of the squares of the regression residuals from the combined data;

$\mathrm{RSS}_{1}$ sum of the squares of the regression residuals from the first group;

$\mathrm{RSS}_{2}$ sum of the squares of the regression residuals from the second group;

$\mathrm{k}$ is the total number of regression parameters;

$\mathrm{n}$ is the number of elements in combined sample (Toyoda, 1974).

If the hypothesis of the absence of a structural break is true, this statistic has a Fisher distribution with $\mathrm{k}$ and $\mathrm{n}-2 \mathrm{k}$ degrees of freedom. If its value is more than critical, it can be concluded that the dependence of the asset's profitability on the 
market profitability has changed over time. Consequently, the beta coefficient calculated by using all historical data can lead to forecast errors, since it does not consider the change that has occurred in the response of the particular company stock to market fluctuations. This check is especially important for emerging stock markets, like the Russian one, as they are more prone to crisis phenomena and are more volatile than developed markets. However, it should be noted that the opposite situation, when the hypothesis of the presence of a structural break is rejected, is not a reason to assert that the calculated beta coefficient will be effective in predicting the profitability of a financial instrument.

The values obtained are compared with critical values for the significance level $\alpha=0.05$ and a sample size of 10 elements.

\subsection{Data used in the calculations}

The calculation was based on market quotes from the RTS index (Russian Trading System) and stocks and bonds of the companies for 2016-2018 measured at intervals of one month, taken from the BCS Express quoting site ${ }^{1}$. Based on the beta coefficients obtained, the forecast value of the annual return on the companies' stocks was calculated and compared with the actual one.

The return on government bonds was used as a risk-free rate. According to the data posted on the official website of the Central Bank of the Russian Federation (Bank of Russia, 2019), at the beginning of January 2019, the yield on government bonds with a maturity of one year was $7.36 \%$ per annum.

For expected market profitability, the Equity Risk Premium (ERP), published by Aswath Damodaran ${ }^{2}$, the most significant modern specialist in share valuation, can be used. As of January 2019, the ERP value for Russia was $9.43 \%$.

To calculate the beta coefficient by using the Monkhouse formula (3), you need to know unlevered beta. The value of this indicator for various sectors of the economy is also published by Aswath Damodaran ${ }^{3}$. When getting that value for Russian companies, it should be adjusted by taking into account expected inflation rates in Russia and in the USA (Luk'yanov, 2015) by using formula (11):

$$
\beta_{U_{R F}}=\beta_{U_{U S A}} \cdot \frac{1+\frac{I_{R F}}{100 \%}}{1+\frac{I_{U S A}}{100 \%}}
$$

1 BrokerCreditService (2019). Quotations. BCS Express (retrieved from https://bcsexpress.ru/kotirovki-i-grafiki).

${ }^{2}$ NYU Stern (2018), CountryERP list. Leonard N. Stern School of Business (retrieved from http://pages.stern.nyu.edu/ adamodar/New_Home_Page/datafile/CountryERPlist.htm).

3 NYU Stern (2019), Betas, Leonard N. Stern School of Business (retrieved from http://pages.stern.nyu.edu/ adamodar/New_Home_Page/datafile/Betas.html). 
where:

$\beta_{\mathrm{U} R \mathrm{~F}}$ is the beta coefficient value for a Russian company that does not use borrowed financing;

$\beta_{\mathrm{U} \text { USA }}$ is the beta coefficient value for an American company that does not use borrowed financing;

$\mathrm{I}_{\mathrm{RF}}$ is the annual inflation rate in Russia as a percentage;

$\mathrm{I}_{\mathrm{USA}}$ is the annual inflation rate in the USA as a percentage.

To determine the beta of debt, a regression analysis is applied of the dependence of coupon-free yields from bonds issued by the companies analyzed on the RTS index's yield. Leverage and weighted average cost of borrowed capital are determined based on data contained in the annual published financial statements of public companies.

The last variable in the Monkhouse formula is the effective income tax rate. According to paragraph 1 of Art. 284 of the Tax Code of the Russian Federation ${ }^{4}$, the corporate income tax rate is $20 \%$.

When calculating according to the two beta model, the industry average published by Aswath Damodaran, adjusted for inflation by using formula (11), was used as the long-term beta coefficient. The short-term beta coefficient was calculated by using formula (1) based on stock quotes and the market index for 2018 taken at intervals of one month. Weighting coefficients were equal to 0.5 , as in the original work where this formula was proposed (Hamidreza and Amin, 2015).

\section{Results}

Beta coefficient values were obtained by using three methods: the traditional Sharpe coefficient is $\beta$; the Monkhouse beta coefficient is $\beta_{\mathrm{L}}$; the coefficient of the two beta model is $\beta_{2}$ and the corresponding projected returns on shares $\left(\mathrm{E}(\beta) ; \mathrm{E}\left(\beta_{\mathrm{L}}\right)\right.$; $E\left(\beta_{2}\right)$ ) of the companies under consideration are presented below (Table 1).

Table1. Expected return on shares of the analyzed companies

\begin{tabular}{llccccc}
\hline Company & \multicolumn{3}{c}{ Beta coefficient } & \multicolumn{3}{c}{ Expected return on shares } \\
\cline { 2 - 7 } & \multicolumn{1}{|}{$\boldsymbol{\beta}$} & $\boldsymbol{\beta}_{\boldsymbol{L}}$ & $\boldsymbol{\beta}_{\mathbf{2}}$ & $\boldsymbol{E}(\boldsymbol{\beta})$ & $\boldsymbol{E}\left(\boldsymbol{\beta}_{\boldsymbol{L}}\right)$ & $\boldsymbol{E}\left(\boldsymbol{\beta}_{\mathbf{2}}\right)$ \\
\hline Gazprom & 0.639 & 1.493 & 0.836 & $8.68 \%$ & $10.45 \%$ & $9.09 \%$ \\
Rosneft & 0.634 & 2.657 & 0.808 & $8.67 \%$ & $12.86 \%$ & $9.03 \%$ \\
Sberbank & 1.050 & 1.862 & 1.088 & $9.53 \%$ & $11.21 \%$ & $9.61 \%$ \\
VTB & 0.478 & 2.435 & 0.630 & $8.35 \%$ & $12.40 \%$ & $8.66 \%$ \\
Rosgosstrakh & -1.902 & 1.689 & 0.390 & $3.43 \%$ & $10.85 \%$ & $8.17 \%$ \\
MOESK & 0.535 & 0.620 & 0.325 & $8.47 \%$ & $8.64 \%$ & $8.03 \%$
\end{tabular}

\footnotetext{
${ }^{4}$ The Federal Law 117-FZ of the Russian Federation (2000), The Federal Law of the Russian Federation dated 05.08.2000 No. 117-FZ "Tax Code of the Russian Federation. Part 2", redaction of 29.09.2019 (retrieved from http://www.garweb.ru/project/mns/en/law/ garweb_law/10800200/10800200-001.htm)
} 


\begin{tabular}{lcccccc}
\hline Company & \multicolumn{3}{c}{ Beta coefficient } & \multicolumn{3}{c}{ Expected return on shares } \\
\cline { 2 - 7 } & $\boldsymbol{\beta}$ & \multicolumn{1}{c}{$\boldsymbol{\beta}_{\boldsymbol{L}}$} & $\boldsymbol{\beta}_{\mathbf{2}}$ & $\boldsymbol{E}(\boldsymbol{\beta})$ & $\boldsymbol{E}\left(\boldsymbol{\beta}_{\boldsymbol{L}}\right)$ & $\boldsymbol{E}\left(\boldsymbol{\beta}_{\boldsymbol{2}}\right)$ \\
\hline RusHydro & 0.527 & 0.404 & 0.428 & $8.45 \%$ & $8.20 \%$ & $8.25 \%$ \\
Sistema & 0.842 & 15.787 & 0.886 & $9.10 \%$ & $40.02 \%$ & $9.19 \%$ \\
KAMAZ & 0.429 & 3.785 & 0.870 & $8.25 \%$ & $15.19 \%$ & $9.16 \%$ \\
MTS & 0.583 & 2.428 & 0.878 & $8.57 \%$ & $12.38 \%$ & $9.18 \%$ \\
\hline
\end{tabular}

Source: Authors' representation

The large Monkhouse beta value for Sistema is due to substantial volumes of borrowed capital used by the company, its leverage being 22,250. This allows for higher returns for shareholders. As can be seen from Figure 1, the real return on this company stock is even higher than that predicted using the Monkhouse beta.

Predicted returns on shares were significantly different from actual ones, and for most companies the forecasts were not satisfactory. Moreover, the estimates obtained using the traditional CAPM and the two beta model vary slightly for different companies, while the real stock returns express a more significant difference. Forecasts based on the Monkhouse beta coefficient vary more noticeably but, for most companies, they also turn out to be below actual values (Figure 1).

Figure 1. The expected, based on beta coefficients, and the actual return on shares of Russian companies

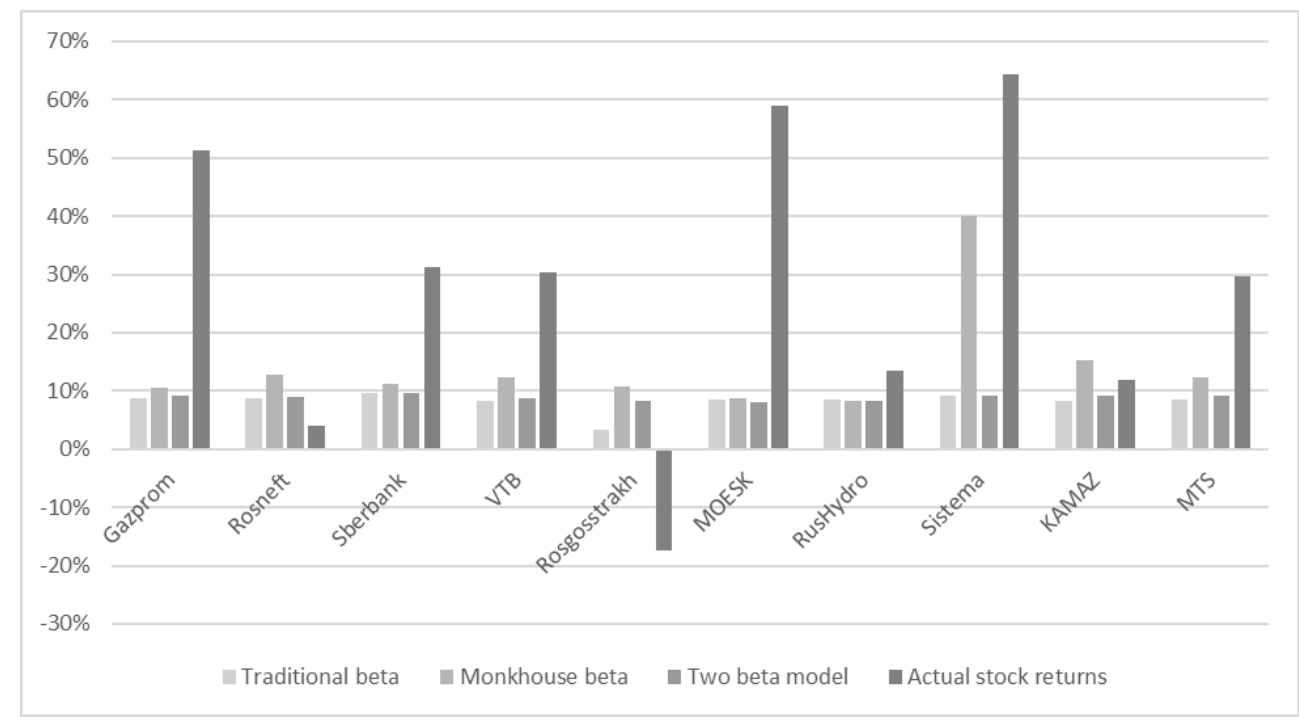

Source: Authors' representation

The critical F-statistic for a sample of ten companies is 2.978. It was more than two times outstripped even for the predictions from the Monkhouse beta coefficient. For other coefficients, the sampling statistics exceeded the critical value 
manifold. This means that the real volatility of stocks of individual companies over the year horizon is significantly higher than predicted by the analyzed CAPM variations, to a greater or lesser extent, based on assumptions about the perfect market. In addition to the values of the predicted and actual stock returns, a visual assessment of the forecasting error magnitude caused by the use of the compared beta coefficients is also appropriate (Figure 2).

Quantitatively, the statement about unrealistically small variation in the forecasts of returns on stocks of different companies can be tested by using the Fisher test, which is calculated for the hypothesis of equality of sample variances for the predicted and actual returns (Table 2).

Table 2. Comparison of variations as the expected, based on beta coefficients, and the actual return on shares of Russian companies

\begin{tabular}{llccc}
\hline & $\boldsymbol{E}(\boldsymbol{\beta})$ & $\boldsymbol{E}\left(\boldsymbol{\beta}_{\boldsymbol{L}}\right)$ & $\boldsymbol{E}\left(\boldsymbol{\beta}_{\mathbf{2}}\right)$ & $\boldsymbol{r}_{\boldsymbol{a}}$ \\
\hline $\begin{array}{l}\text { Unbiased sample } \\
\text { variance }\end{array}$ & $2.90 \times 10^{-4}$ & $8.63 \times 10^{-3}$ & $2.80 \times 10^{-5}$ & $6.64 \times 10^{-2}$ \\
\hline F-test & 228.939 & 7.693 & 2369.978 & \\
\hline
\end{tabular}

Source: Authors' calculations

Figure 2. Return on shares of Russian companies forecasting errors

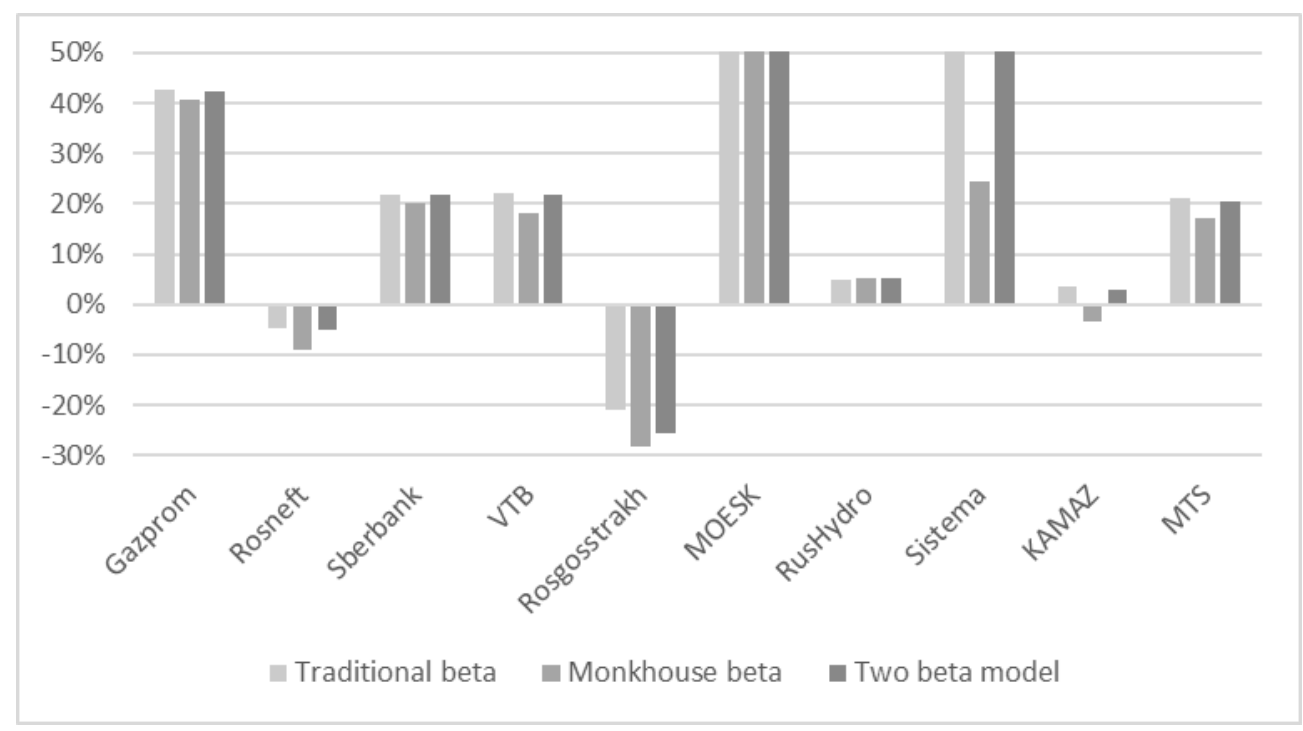

Source: Authors' calculations

For most companies, errors are positive. That is, the predicted profitability of shares is understated relative to the actual one. The arithmetic mean error when using 
the traditional Sharpe coefficient is $19.64 \%$; for the Monkhouse beta coefficient, it is $13.57 \%$; for the two beta models, it is $18.95 \%$. Median error is $21.39 \%, 17.63 \%$, and $21.05 \%$, respectively. That is, in addition to the fact that the estimates of stock returns have a significantly lower variability than the real one, they are biased for the studied sample of large Russian companies.

After comparing the forecast values obtained with the actual ones observed based on the results of 2019, it is evident that none of the beta coefficient calculation methods offers a noticeable advantage (Table 3 ).

Table 3. The difference between the predicted and actual stock returns of the analyzed companies

\begin{tabular}{lrrrr}
\hline Company & $\begin{array}{l}\text { Actual stock } \\
\text { returns }\end{array}$ & \multicolumn{2}{l}{$\begin{array}{l}\text { The difference between the predicted and actual } \\
\text { value (absolute) }\end{array}$} \\
\cline { 2 - 5 } & & \multicolumn{1}{|c}{$\left|\boldsymbol{r}_{\boldsymbol{a}}-\boldsymbol{E}(\boldsymbol{\beta})\right|$} & $\left|\boldsymbol{r}_{\boldsymbol{a}}-\boldsymbol{E}\left(\boldsymbol{\beta}_{\boldsymbol{L}}\right)\right|$ & $\left|\boldsymbol{r}_{\boldsymbol{a}}-\boldsymbol{E}\left(\boldsymbol{\beta}_{\mathbf{2}}\right)\right|$ \\
\hline Gazprom & $51.30 \%$ & $42.62 \%$ & $40.85 \%$ & $42.21 \%$ \\
Rosneft & $3.90 \%$ & $4.77 \%$ & $8.96 \%$ & $5.13 \%$ \\
Sberbank & $31.29 \%$ & $21.76 \%$ & $20.08 \%$ & $21.68 \%$ \\
VTB & $30.45 \%$ & $22.10 \%$ & $18.06 \%$ & $21.79 \%$ \\
Rosgosstrakh & $-17.49 \%$ & $20.92 \%$ & $28.35 \%$ & $25.66 \%$ \\
MOESK & $59.03 \%$ & $50.56 \%$ & $50.39 \%$ & $51.00 \%$ \\
RusHydro & $13.37 \%$ & $4.92 \%$ & $5.18 \%$ & $5.12 \%$ \\
Sistema & $64.46 \%$ & $55.36 \%$ & $24.45 \%$ & $55.27 \%$ \\
KAMAZ & $11.94 \%$ & $3.70 \%$ & $3.25 \%$ & $2.79 \%$ \\
MTS & $29.59 \%$ & $21.02 \%$ & $17.21 \%$ & $20.41 \%$ \\
\hline
\end{tabular}

Source: Authors' calculations

After averaging the error values obtained, the arithmetic mean absolute error when using the traditional Sharpe coefficient is $24.77 \%$; for the Monkhouse beta coefficient, it is $21.68 \%$; for the two beta model, it is $25.11 \%$. The Median absolute error is $21.39 \%, 19.07 \%$, and $21.73 \%$, respectively. Thus, there is some superiority in the accuracy of calculations using the Monkhouse beta coefficient. To determine its probable causes and formulate further conclusions, we must turn to the criteria for checking sample homogeneity: the Student's t-test, the Mann-Whitney U-test and the Wilcoxon signed-rank test.

We compared the statistical values we obtained for these criteria with the critical values. The comparison results are presented below (Table 4). 
Table 4. Results of testing the sample homogeneity hypothesis

\begin{tabular}{|c|c|c|c|c|}
\hline \multirow{2}{*}{ Criterion } & \multicolumn{3}{|c|}{ Resulting statistical value } & \multirow{2}{*}{ Critical value } \\
\hline & $\beta_{L}$ vs. $\beta$ & $\beta_{L}$ Vs. $\beta_{2}$ & $\beta$ vs. $\beta_{2}$ & \\
\hline $\begin{array}{l}\text { Student's } \quad \text { t-test } \quad t- \\
\text { criterion }\end{array}$ & 0.944 & 1.095 & 0.654 & 1.833 \\
\hline Mann-Whitney U-test & 44 & 44 & 48 & 23 \\
\hline Wilcoxon T-criterion & 19 & 18 & 25 & 10 \\
\hline
\end{tabular}

Source: Authors' calculations

Consequently, none of the criteria can reject the null hypothesis of sample homogeneity and admit the superiority of one beta coefficient over another for all pairs of compared models. Moreover, when checking three pairs of coefficients by three criteria, multiple comparisons are actually made, so the only excess of the critical level could be considered accidental (Chen et al., 2017). However, it allows us to assert with high confidence that the difference in the average accuracy of forecasts made using different models is due to random factors.

Chow criterion dependence stability checking showed that, for the shares of Gazprom, Sberbank, there is a statistically significant difference in the subsamples of returns in 2016-2017 and returns in 2018, which can serve as an additional indicator of the unreliability of forecasts obtained for these companies using traditional CAPM based on a three-year beta coefficient (Table 5).

Table 5. Structural break checking results

\begin{tabular}{lcc}
\hline Company & Chow test statistics & Critical value \\
\hline Gazprom & 4.985 & 4.130 \\
Rosneft & 3.862 & 4.130 \\
Sberbank & 8.232 & 4.130 \\
VTB & 0.159 & 4.130 \\
Rosgosstrakh & 1.156 & 4.130 \\
MOESK & 2.733 & 4.130 \\
RusHydro & 1.584 & 4.130 \\
Sistema & 0.147 & 4.130 \\
KAMAZ & 0.394 & 4.130 \\
MTS & 0.383 & 4.130 \\
\hline
\end{tabular}

Source: Authors' calculations

In general, it can be noted that, for the shares of most companies, there was no statistically significant structural shift in the dependence of their profitability on the market average. But, despite this, the predictions obtained using the CAPM and its variations, namely, the two beta model and the model using the Monkhouse beta 
coefficient, possess no acceptable accuracy for practical use. This indicates the criticality of non-tradable risk factors for Russian stocks.

\section{Discussion}

The stock returns of the largest Russian companies predicted by using the CAPM turned out to be significantly different from the real returns, regardless of the beta coefficient applied. These results are consistent with the conclusions about the low explanatory power of models that only consider trading risk from previous empirical studies of the Russian stock market (Dedyuhin, 2019; Fedorova et al., 2017).

Moreover, estimates of stock returns obtained for individual companies turn out to be biased on average. It follows that, in the case of predicting the profitability of not individual stocks of companies representing various sectors of the Russian economy, but a portfolio made up of them, the use of CAPM, both with the traditional beta coefficient as well as with Monkhouse or the coefficient of the twobeta model, will still result in a substantially inaccurate forecast.

A common feature of the forecasts obtained using all the considered beta coefficients modifications is that the variation of the predicted values of the returns on shares of various large Russian companies turns out to be incomparably lower than the real variation of their returns. The forecasts obtained with the Monkhouse beta coefficient have a slightly higher variability than others obtained in this study, but even for their sample, the hypothesis of equality of variances when compared with a sample of actual returns is rejected for the traditional economic research level of 5\% significance. Thus, it can be argued that, even for large companies whose shares have been traded on the Russian stock market for a long time, volatility cannot be fully explained by tradable risk alone.

Consequently, the most probable reason for the deviation of the predicted results from the actual ones is that the CAPM only takes into account systematic risk. However, in the real conditions of an imperfectly developing stock market, such as the Russian one, non-trading risk also has a significant impact on returns on an asset (Hur and Chung, 2017).

All criteria testify to the homogeneity of difference samples between the predicted and actual stock returns. Therefore, it is impossible to assert with high confidence that the identified superiority of calculations performed using the Monkhouse beta coefficient is natural and not caused by external random factors.

The Monkhouse beta coefficient does have an insignificant advantage, but only for companies that have great financial leverage, such as banks (Sberbank 6.078; VTB - 7.696) or investment corporations (AFK Sistema - 22.250). Nevertheless, it remains insignificant against the background of the overall high error of all the models under consideration.

Similar conclusions were drawn in a study of the Belgrade Stock Exchange. For shares traded on it, no advantage was found in the accuracy of forecasts obtained 
by using a modified CAPM (Stancic et al., 2015). Similar studies of the Turkish (Yayvak et al., 2015) and Indian (Bajpai and Sharma, 2015) stock markets, which, like the Russian one, are considered to be developing, on the contrary, revealed the notable superiority of modified beta coefficients over the Sharpe coefficient, which was not deemed accurate.

The results of this study prove that calculating expected returns on shares in Russian companies by using Sharpe beta coefficients, Monkhouse and two beta model coefficients does not ensure reliable forecasting. The average bias in the estimates of stock returns relative to the actual values exceeds the risk-free rate of return on government bonds with a similar maturity. This is unacceptable for practical forecasts. Moreover, there is a problem not only with the accuracy but also with the variability of the forecast. That is, traditional and modified versions of the capital asset pricing model, as a rule, predict the value of stock returns much closer to the risk-free rate of return than that later on observed in reality.

\section{Conclusions}

To summarize the above, in contemporary market conditions, directly calculating the beta coefficient by using formula (1) proposed by William F. Sharpe in 1964 does not produce accurate results in most cases. Subsequent modifications, in particular, Monkhouse (3) and the two beta model (4), did not show a clear improvement in forecasting accuracy when tested on the Russian stock market. None of these modifications should be considered reliable tools for predicting the profitability of shares traded on the Russian stock exchange, nor should they be used in making investment decisions. Furthermore, since the allocation of the short-term and long-term beta coefficient for the two beta model or beta of debt in the Monkhouse formula complicates the calculation and collection of data, in practice, these modifications of the beta coefficients cannot be used as an equivalent alternative to the traditional one.

This study was conducted on a sample of companies from different industries, which enables generalizing the results obtained to a wide range of Russian companies. The relatively small sample size, due to the difficulty of collecting relevant data for calculating the beta of debt, makes it possible to refine the estimates of the mean forecast errors by using the considered models. However, the use of robust criteria of sample homogeneity and a significant excess of their calculated statistics of critical values for the $95 \%$ significance level allows asserting with high confidence that the conclusions about the indistinguishable low forecasting accuracy of the considered models will be confirmed in other studies.

The resulting forecasts of the company's stock returns were biased relative to the actual values. Moreover, the average error for them exceeds the risk-free rate of return on government bonds with a similar maturity. Therefore, there are reasons to believe that, while predicting the profitability of either individual stocks or a 
portfolio diversified by economic sectors, by using the considered modifications of beta coefficients, it is impossible to obtain forecasts with a satisfactory level of accuracy in order to make practical investment decisions.

It is notable that the common feature found for all of the reviewed beta coefficients is the unrealistically low variance of stock return forecasts for different companies. On the one hand, this confirms the thesis about the imperfection of the Russian stock market, where non-tradable risk factors have a greater impact on stock returns than market risk. On the other hand, it allows concluding about the low predictive accuracy of CAPM and its modifications in general.

Besides, for some companies from the provided sample, on the historical horizon, based on which beta coefficients were calculated, there was a structural break in the dependence of stock returns on market returns. This means that the longterm beta ratios calculated for similar stocks probably represent an attempt of approximation of two different trends observed in different historical periods with one dependence. Theoretically, this problem can be circumvented through the coefficient of the two beta model. But in fact, the forecasts obtained by relying on it also turned out to be unsatisfactory.

Thus, CAPM and its modifications are, in most cases, expected to be ineffective in predicting the performance of individual stocks and portfolios, including of diversified ones. But since the key condition for the attractiveness of investing in the stock market is the reliability of predictions of the profitability of traded assets, the issue of choosing an accurate and stable forecasting model remains relevant. This provides a great potential for further research aimed at assessing the existing models for predicting the profitability of stocks of companies traded on emerging stock markets, including the Russian market, as well as for research aimed at developing new or modified models. A further direction for this research on more accurate methods for predicting stock returns is focused on models that allow for the non-market risks of traded assets to be taken into account. For instance, adjusted hybrid capital asset pricing model (AH-CAPM) (Pereiro, 2002) or Multifactor Asset Pricing Model (Ericsson and Karlsson, 2003).

These models were created to predict the performance of stocks traded in the stock markets with pronounced deviations from the assumptions required for the fairness of the traditional CAPM. By introducing adjustments for additional factors, theyshould theoretically make it possible to build forecasts less dependent on random fluctuations in the quotes of specific instruments and, due to this, they should more accurately predict the industry average return on stocks of companies depending on external market conditions.

However, it is important to emphasize that they also have some of the disadvantages inherent in the modifications of the beta coefficients discussed in this paper and the CAPM in which they are used.

Hybrid model forecasts, as exemplified by the AH-CAPM, are based on expected returns on mature market peers. By introducing an adjustment for risks 
caused by the relative volatility of the local market in comparison with the volatility of the global market, it is assumed to obtain a robust estimate of the expected return on shares of an individual company. But, at the same time, part of the information about the specificities of a particular company's activities is inevitably lost. At the same time, this study has, on the contrary, demonstrated that even the traditional CAPM forecasts, which take into account the high volatility of the local market, have a variance that is incomparably lower than the actual return on stocks of companies on the market for the same period. This suggests that AH-CAPM will also offer an estimate of expected stock returns close to the industry average, while real returns for most stocks will be significantly different from those predicted.

The Multifactor Asset Pricing Model is based on the market performance of the stock of a particular company, as well as on macroeconomic and industry indicators. It can be further assumed that it will be most appropriate for developed stock markets with less volatility of traded assets. And for the developing Russian market, as in the case of CAPM, the situation is likely that the real spread of returns on large companies' shares will be higher than the predicted one due to some specific factors that are not considered by the model.

Therefore, another alternative direction of search for better means of predicting the returns on stocks and other financial instruments are more complex models, not purely financial, but belonging to the class of machine learning models. Moreover, at present, deep learning models seem to be more promising, enabling to first identify the data, and then use it in forecasting the complex patterns that are difficult to find and describe by using traditional methods (Karahan and Colak, 2019).

In general, machine learning trading models can be based on various categories of inputs. First, and most obviously, the same historical stock and market index data as in CAPM forecasting can be used. However, even on their basis, by using models that are significantly more complex than linear regression, it is theoretically possible to identify real-life and reproducible patterns that are not taken into account in the CAPM.

For example, studies (Huang et al., 2020; Pang et al., 2020) show that using long-term memory neural networks that take as input not just historical quotes or yields but their certain combination converted into a so-called "stock vector" by using dimensionality reduction methods can be effective.

Secondly, different financial ratios, such as Net Tangible Asset, Liquid Asset, Debt to Equity, Asset Turnover, etc. (Siew and Nordin, 2012) can be used for the analyzed company. They provide a more extended description of the activities of a particular company, which can allow for a more accurate prediction of the profitability of its shares by taking into account the specificities that cannot be identified based on traded indicators only. And, due to this, on average, more precise and varied forecasts for specific stocks compared to CAPM with modified or traditional beta are obtained. 
Additionally, along with the stock, financial and macroeconomic indicators, which are quantified for specific companies, management decisions have an impact on stock returns (Khan et al., 2011). Moreover, the impact of these decisions can have both short-term and long-term consequences that affect the profitability of the company's shares. Accordingly, automated processing and analysis of open data for such solutions may constitute the next direction for modifying machine learning models developed to predict the return on stocks of individual companies.

Probably, by using machine learning models, it will be possible to build forecasts with statistically significant superiority in accuracy over those obtained by using CAPM and its variants which involve various modifications of beta coefficients. Moreover, by using deep learning models, the authors provide the possibility to predict not only medium-term but also short-term profitability, which is of no less interest from a practical point of view when conducting arbitrage trading. Meanwhile, the relevance of using CAPMs, and specifically CAPMs with modified beta coefficients, in the modern Russian stock market, has already been exhausted.

\section{References}

Analytical Center for the Government of the Russian Federation (2019), Trends and Structure of Russia's GDP, Bulletin on Current Trends in Russian Economy, 48.

Bajpai, S. and Sharma, A.K. (2015), An empirical testing of capital asset pricing model in India, Procedia Social and Behavioral Sciences, 189, pp. 259-265. https://doi.org/10.1016/j.sbspro.2015.03.221

Bank of Russia (2019), Russian government bond zero coupon yield curve: graph, The Central Bank of the Russian Federation (Bank of Russia) official site.

Banks Around the World (2017), World's largest stock exchanges, Relbanks (retrieved from https://www.relbanks.com/stock-exchanges/largest-stock-exchanges).

Bukhvalov, A.V. (2016), Managerial theory of firm: towards a synthesis of finance and strategic management, Russian Management Journal, 14(4), pp. 105-126.

Chang, W. (2015), The term structure of CAPM Alphas and Betas, SSRN Electronic Journal. http://dx.doi.org/10.2139/ssrn.2616934

Chen, S.Y., Feng, Z. and Yi, X. (2017), A general introduction to adjustment for multiple comparisons, Journal of thoracic disease, 9(6), pp. 1725-1729. https://doi.org/10.21037/jtd.2017.05.34

Cole, S., Melecky, M., Molders, F. and Reed, T. (2020), Long-run Returns to Impact Investing in Emerging Market and Developing Economies, Policy Research Working Paper, No. 9366, World Bank, Washington, DC.

Damodaran, A. (1999), Estimating risk parameters, New York: Stern School of Business.

Dedyuhin, V.A. (2019), Problems of using the CAPM model to estimate the cost of equity in the Russian stock market, Colloquium-Journal, 9(33), pp. 144-146. 
Fama, E.F. and French, K.R. (1993), Common risk factors in the returns on stocks and bonds, Journal of Financial Economics, 33(1), pp. 3-56. https://doi.org/10.1016/0304405X(93)90023-5

Fedorova, E.A., Guzovskii, Y.G. and Lukashenko, I.V. (2017), Evaluating the applicability of modified beta coefficient in the Russian stock market, Economic Analysis: Theory and Practice, 16(11), pp. 2163-2176. https://doi.org/10.24891/ea.16.11.2163.

Glagoleva, L.A. (2008), Interest rate as a characteristic of stock returns in the capital asset pricing model, Economic Bulletin of Rostov State University, 6(3, part 2), pp. 32-37.

Hamidreza, V.F. and Amin. B.F. (2015), A new modified CAPM model: The two Beta CAPM, Journal UMP Social Sciences and Technology Management, 3(1), pp. 343-346.

Huang, J., Chai, J. and Cho, S. (2020), Deep learning in finance and banking: A literature review and classification, Frontiers of Business Research in China, 14(13), pp. 1-24. https://doi.org/10.1186/s11782-020-00082-6

Hur, S.K. and Chung, C.Y. (2017), Revisiting CAPM betas in an incomplete market: Evidence from the Korean stock market, Finance Research Letters, 21, pp. 241-248. https://doi.org/10.1016/j.frl.2016.12.018

Jadhav, S., He, H. and Jenkins, K. (2015), Prediction of earnings per share for industry, in Proceedings of the 7th International Joint Conference on Knowledge Discovery, Knowledge Engineering and Knowledge Management. https://doi.org/10.5220/0005616604250432

Karahan, O. and Colak, O. (2019), The link between financial capital movements and the exchange rate in Turkey, Eastern Journal of European Studies, 10(2), pp. 263-281.

Khan, K., Amin, I.U. and Ahmed, S. (2011), Management decisions, stock prices and the economy, International Research Journal of Finance and Economics, 75, pp. 7-13.

Kokotkina, T.N., Kulalaeva, I.V., Mihajlova, S.M. and Sadovin, N.S. (2017), The assessment of profitability and value of assets, News of the Tula State University. Economic and legal sciences, 1(1), pp. 12-21.

Korolev, S.A. and Yazev, M.V. (2020), Analysis of the applicability of CAPM modifications for medium-term forecasting in the Russian stock market, Journal of Economy and Entrepreneurship, 5(118), pp. 791-796. https://doi.org/10.34925/EIP.2020.118.5.161

Lemeshko, B. Yu. and Lemeshko, S.B. (2008), Power and robustness of criteria used to verify the homogeneity of means. Measurement Techniques, 51(9), pp. 950-959. https://doi.org/10.1007/s11018-008-9157-3

Luk'yanov, K.A. (2015), Methods of estimation of beta coefficient on the example of Norilsk Nickel, Current trends in science and technology, 9(6), pp. 87-92.

Masoud, N.M.H. (2013), The impact of stock market performance upon economic growth, International Journal of Economics and Financial Issues, 3(4), pp. 788-798.

Mensah, L. (2013), The behaviour of beta in the 19th century, Accounting and Finance Research, 2(4) (retrieved from https://doi.org/10.5430/afr.v2n4p34). 
Money Online Ltd and Investment Research Group Ltd (2002), What are imputation credits? ShareChat (retrieved from http://www.sharechat.co.nz/article/053d0451/what-areimputation-credits.html).

Monkhouse, P.H.L. (1997), Adapting the APV valuation methodology and the beta gearing formula to the dividend imputation tax system, Accounting \& Finance, 37(1), pp. 6988. https://doi.org/10.1111/j.1467-629x.1997.tb00314.x

Orlov, A.I. (2016), Testing of homogeneity of paired samples, Polythematic Online Scientific Journal of Kuban State Agrarian University, 123, pp. 708-726.

Pang, X., Zhou, Y., Wang, P., Lin,W. and Chang, V. (2020), An innovative neural network approach for stock market prediction, The Journal of Supercomputing, 76(1), pp. 2098 2118. https://doi.org/10.1007/s11227-017-2228-y

Podkopaev, O.A. (2015), Methods and approaches to the calculation of the beta coefficient to determine the rate of discounting of financial and real investment, International Journal of Applied and Fundamental Research, 3, pp. 245-249.

Roll, R. (1977), A critique of the asset pricing theory's tests Part I: On past and potential testability of the theory, Journal of Financial Economics, 4(2), pp. 129-176. https://doi.org/10.1016/0304-405x(77)90009-5.

Rossi, M. (2016), The capital asset pricing model: a critical literature review, Global Business and Economics Review, 18(5), pp. 604-617. https://doi.org/10.1504/GBER.2016.078682

Semenyuk, V. (2016), Pragmatics of using a modified CAPM model for estimating cost of equity on emerging markets, Baltic Journal of Economic Studies, 2(2), pp. 135-142. https://doi.org/10.30525/2256-0742/2016-2-2-135-142.

Siew, L. and Nordin, M.J. (2012), Regression techniques for the prediction of stock price trend, Conference: Statistics in Science, Business, and Engineering (ICSSBE), Langkawi, Malaysia, 2012, pp. 1-5. https://doi.org/10.1109/ICSSBE.2012.6396535

Stancic, V., Petrović, E. and Radivojević, N. (2015), Conditional relationship between beta and returns: a case study of the Belgrade stock exchange, Themes: Journal of Social Sciences, 39(4), pp. 1165-1182.

Toyoda, T. (1974), Use of the Chow test under heteroscedasticity, Econometrica, 42(3), pp. 601-608. https://doi.org/10.2307/1911796

Verma, R. (2011), Testing the Forecasting power of the conditional relationship between beta and return, Journal of Risk Finance, 12(1), pp. 69-77.

Vukolov, E.A. (2012), Fundamentals of statistical analysis. Workshop on statistical methods and operations research using STATISTIS and EXCEL packages, Moscow: Forum.

Yayvak, B., Akdeniz, L. and Altay-Salih, A. (2015), Do time-varying betas help in asset pricing? Evidence from BorsaIstanbul, Emerging Markets Finance and Trade, 51(4), pp. 747-756. https://doi.org/10.1080/1540496x.2015.1046346

Zozulya, V.V. and Korolev, S.A. (2018), Conditions for using different types of adjusted beta to calculate return on assets, Economic Analysis: Theory and Practice, 17(9), pp. 17811796. https://doi.org/10.24891/ea.17.9.1781 